\title{
Screening of differentially expressed proteins from syncytiotrophoblast for severe early-onset preeclampsia in women with gestational diabetes mellitus using tandem mass tag quantitative proteomics
}

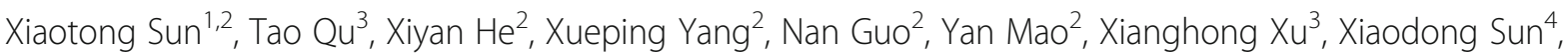
Xuehong Zhang ${ }^{1,5,6^{*}}$ and Weihua Wang ${ }^{7 *}$

\begin{abstract}
Background: Previous studies have revealed that women with gestational diabetes mellitus (GDM) have an increased risk of developing preeclampsia (PE). The possible reason is the abnormal lipid metabolism caused by GDM that leads to dysfunction of vascular endothelial cells and atherosclerosis, resulting in the onset of PE. However, studies focusing on the pathogenesis of PE in syncytiotrophoblast of GDM patients are lacking. This study aimed to compare differentially expressed proteins from syncytiotrophoblast between women with GDM and women with GDM with subsequently developed PE.

Methods: Syncytiotrophoblast samples were obtained from pregnant women immediately after delivery. To explore the protein expression changes of syncytiotrophoblast that might explain the pathogenesis of PE in women with GDM, quantitative proteomics was performed using tandem mass tag (TMT) isobaric tags and liquid chromatography-tandem mass spectrometry. Bioinformatics analysis was performed to enrich the biological processes that these differentially expressed proteins were involved in.

Results: A total of 28,234 unique peptides and 4140 proteins were identified in all samples. Among them, 23 differentially expressed proteins were identified between patients with GDM and patients with GDM with subsequently developed PE. Therein, 11 proteins were upregulated and 12 proteins were downregulated. Two relative proteins ( $F L T 1$ and PABPC4) were independently verified using immunoblotting analysis. Bioinformatic results indicated that the onset of PE in patients with GDM is a multifactorial disorder, involving factors such as apoptosis, transcriptional misregulation, oxidative stress, lipid metabolism, cell infiltration and migration, and angiogenesis.
\end{abstract}

Conclusion: These results indicated that the inadequacy of endometrium infiltration, angiogenic disorder, and oxidative stress in syncytiotrophoblast are more likely to occur in patients with GDM and may be the potential mechanisms leading to such patients secondarily developing severe early-onset PE.

Keywords: Preeclampsia, Gestational diabetes mellitus, Syncytiotrophoblast, TMT technology, Biomarkers

\footnotetext{
* Correspondence: zhangxueh@|zu.edu.cn; wangweihua11@yahoo.com

${ }^{1}$ The First Clinical Medical College, Lanzhou University, Lanzhou, China

${ }^{7}$ Houston Fertility Laboratory, Houston, TX, USA

Full list of author information is available at the end of the article
}

(c) The Author(s). 2018 Open Access This article is distributed under the terms of the Creative Commons Attribution 4.0 International License (http://creativecommons.org/licenses/by/4.0/) which permits unrestricted use, distribution, and reproduction in any medium, provided you give appropriate credit to the original author(s) and the source, provide a link to the Creative Commons license, and indicate if changes were made. The Creative Commons Public Domain Dedication waiver (http://creativecommons.org/publicdomain/zero/1.0/) applies to the data made available in this article, unless otherwise stated. 


\section{Background}

Preeclampsia (PE), which is one of the major causes of maternal and perinatal mortality or serious morbidity, is a common pregnancy-specific placental disease, affecting at least $5 \%$ of pregnant women [1-3]. PE is characterised by new-onset maternal hypertension and proteinuria after 20 weeks' gestation $[3,4]$. According to the onset time, PE can be divided into two subtypes: early-onset subtype, occurring before 34 weeks of gestation, and late-onset subtype, occurring from 34 weeks [5]. Although the known pathogenesis of $\mathrm{PE}$ is so diverse and complex that no hypothesis has so far covered all the causes, recent studies suggest that the early-onset and late-onset subtypes arise from different etiopathogenic causes. Early-onset PE is associated with abnormal placental function, mainly manifested in the insufficient invasion of the maternal myometrium by the trophoblast cells, which results in uterine spiral artery remodelling disorder and placental superficial implantation. Late-onset PE is associated with maternal predisposition to arterial diseases, developed due to interfering endothelial function by obesity, diabetes, lipid metabolism dysfunction, and inflammation [1, 6-8].

Gestational diabetes mellitus (GDM) also is a pregnancy-specific disease, characterised by the new onset of any degree of glucose intolerance during pregnancy [9]. Although GDM and PE share several similar risk factors such as increased pre-pregnancy body mass index (BMI) and maternal age as well as multiple gestation pregnancies, GDM was found to be an independent risk factor for PE $[10,11]$. Women with GDM have an increased risk of developing PE [12-14]. One reason is that abnormal lipid metabolism caused by GDM leads to dysfunction of vascular endothelial cells and atherosclerosis [15]. This reason is consistent with the pathogenesis of late-onset PE.

Recently, high-throughput proteomic technology has been widely applied to screen differentially expressed proteins in different tissues of the placenta, plasma, syncytiotrophoblast extracellular vesicles, and umbilical artery from patients with PE [3, 16-19]. These studies partly revealed the potential pathogenesis of PE and identified candidate biomarkers to predict the occurrence of PE during pregnancy. $\mathrm{Li}$ et al. found that the level of plasma fatty acid-binding protein 4 (FABP4) in patients with PE in the GDM group was significantly higher than that in the GDM group, suggesting that plasma FABP4 level could predict the occurrence of PE in women with GDM [20]. However, no studies using high-throughput proteomic analysis to screen differentially expressed proteins between patients with GDM and patients with GDM with subsequently developed PE have been conducted. Therefore, this study aimed to establish a comparative proteomics of the syncytiotrophoblast in patients with GDM and patients with GDM with subsequently developed PE using the tandem mass tag (TMT) quantitative technology, in the hope of identifying candidate biomarkers for predicting PE from patients with GDM and providing targets for future therapy in women with PE with GDM.

\section{Methods \\ Sample collection}

This study was approved by the Ethical Committee of the Gansu Provincial Hospital. All study participants agreed to the sample collection and provided written informed consent. The inclusion criteria for all participants were the following: informed consent to participate in this study, age between 18 and 35 years, singleton pregnancy, absence of diabetes mellitus, hypertension, kidney disease, cardiovascular disease before pregnancy, and not taking any medication. A total of 24 patients with GDM were diagnosed according to a 75-g oral glucose tolerance test (OGTT) at 24-28 weeks of gestation (fasting $\geq 5.1 \mathrm{mmol} / \mathrm{L}, 2 \mathrm{~h} \geq$ $8.5 \mathrm{mmol} / \mathrm{L}$ ). All pregnant women with GDM were treated with diet without insulin intervention. Among them, 9 patients developed severe PE according to systolic blood pressure $(\mathrm{SBP}) \geq 160 \mathrm{mmHg}$ and/or diastolic blood pressure $(\mathrm{DBP}) \geq 110 \mathrm{mmHg}$ and proteinuria $>3 \mathrm{~g} / 24 \mathrm{~h}$ and selected as cases.

Placental samples of the 9 patients with GDM and 9 patients with PE with GDM were obtained after the participants' delivery at the Gansu Provincial Hospital. The syncytiotrophoblasts were separated from the placental samples within $30 \mathrm{~min}$, frozen immediately in liquid nitrogen, and stored at $-80^{\circ} \mathrm{C}$.

\section{Protein extraction}

Three samples from the 9 patients with GDM or 9 patients with PE with GDM were randomly selected as one biological parallel. An equal amount of syncytiotrophoblast sample from each patient was pooled and ground into powder in liquid nitrogen. All of the mixed samples were homogenised using homogeniser in SDT1 buffer (4\% SDS, $1 \mathrm{mmol}$ DTT, $100 \mathrm{mmol}$ Tris-HCl, pH 7.6). Protein extraction was performed by sonication (Power $80 \mathrm{~W}$, work $10 \mathrm{~s}$, interval $10 \mathrm{~s}$, cycle 10 times) on ice and then was boiled for $15 \mathrm{~min}$. The crude extract was centrifuged at 14,000 g for $40 \mathrm{~min}$ to collect the supernatant. The supernatant was filtered with $0.22-\mu \mathrm{m}$ filters and quantified with the BCA Protein Assay Kit (Bio-Rad, USA). The filtrates were stored at $-80{ }^{\circ} \mathrm{C}$ for future use.

\section{Protein digestion and TMT labelling}

Protein digestion was performed using filter-aided sample preparation (FASP) procedure as described before [19]. Briefly, $200 \mu \mathrm{g}$ of total proteins from each pool was diluted in $30 \mu \mathrm{l} \mathrm{SDT} 2$ buffer (4\% SDS, $100 \mathrm{mmol}$ DTT, $150 \mathrm{mmol}$ Tris- $\mathrm{HCl}, \mathrm{pH} 8.0$ ), boiled for $5 \mathrm{~min}$, and cooled to $25^{\circ} \mathrm{C}$. The proteins were washed using washing buffer $(8 \mathrm{M}$ urea, 
150 mmol Tris- $\mathrm{HCl}, \mathrm{pH} 8.0$ ) by repeated ultrafiltration (Microcon units, $10 \mathrm{kD}$ ) at 14,000 g for $15 \mathrm{~min}$ to remove the low-molecular-weight components. Each filter was added in $100 \mu$ lodoacetamide (100 mM iodoacetamide in washing buffer) for blocking reduced cysteine residues, incubated in darkness for $30 \mathrm{~min}$, and then centrifuged to discard the filtrate. The filter was washed three times using $100 \mu \mathrm{l}$ washing buffer and $100 \mu \mathrm{l}$ of $100 \mathrm{mM}$ TEAB buffer. Then, 4- $\mu \mathrm{g}$ trypsin (Promega, USA), revolved in 40- $\mu \mathrm{l}$ TEAB buffer, was added to digest the protein suspension overnight at $37^{\circ} \mathrm{C}$. Finally, the resulting peptides were collected via centrifugation, and the concentrations were calculated according to OD280.

About $100 \mu \mathrm{g}$ of each resulting peptide mixture was labelled using TMT reagent according to the manufacturer's instructions (Thermo Fisher Scientific, USA). Specifically, three syncytiotrophoblast samples from patients with GDM were labelled with $128 \mathrm{~N}, 128 \mathrm{C}$, and $129 \mathrm{~N}$ isobaric TMT tags, while the other three syncytiotrophoblast samples from patients with PE with GDM were labelled with 129C, $130 \mathrm{~N}$, and $130 \mathrm{C}$ isobaric TMT tags, respectively. After TMT labelling, the digested sample was fractionated into 10 fractions, and the excess label and salts were removed, according to Pierce High pH Reversed-Phase Fractionation Kit Manual (Thermo Fisher Scientific).

\section{Liquid chromatography-mass spectrometry/mass spectrometry analysis}

Each fraction, dissolved into solution A ( $0.1 \%$ formic acid), was loaded into a reverse phase trap column (Thermo Scientific Acclaim PepMap100, $100 \mu \mathrm{m} \times 2 \mathrm{~cm}$, nanoViper C18) connected to the C18-reversed phase analytical column (Thermo Scientific Easy Column, $10 \mathrm{~cm}$ long, 75- $\mu \mathrm{m}$ inner diameter, 3- $\mu \mathrm{m}$ resin) and separated with a linear gradient of solution B (84\% acetonitrile and $0.1 \%$ formic acid) at a flow rate of $300 \mathrm{~nL} / \mathrm{min}$. The linear gradient was processed as follows: $0-55 \%$ solution B for $80 \mathrm{~min}, 55-100 \%$ solution B for $5 \mathrm{~min}$, and 100\% solution B for $5 \mathrm{~min}$.

Ten fractions from each sample were analysed using liquid chromatography-mass spectrometry/ mass spectrometry (LC-MS/MS) by Q Exactive Mass Spectrometer coupled to Easy nLC (Thermo Scientific) in positive ion mode for $90 \mathrm{~min}$. MS data was acquired using a data-dependent top10 method, dynamically choosing the most abundant precursor ions from the survey scan $(300-1800 \mathrm{~m} / \mathrm{z})$ for higher-energy collisional dissociation (HCD) fragmentation. The instrument parameters were set as follows: automatic gain control target was 3e6; dynamic exclusion duration, $40 \mathrm{~s}$; resolution for survey scans, 70,000 at $\mathrm{m} / \mathrm{z} 200$; resolution for $\mathrm{HCD}$ spectra, 35,000 at $\mathrm{m} / \mathrm{z} 200$; and isolation width, $2 \mathrm{~m} / \mathrm{z}$. Normalised collision energy was $30 \mathrm{eV}$, and the underfill ratio was $0.1 \%$.

\section{Data analysis}

The acquired MS spectra were analysed using MASCOT search engine (version 2.2; Matrix Science, London, UK) embedded into Proteome Discoverer 1.4 (Thermo Electron, San Jose, CA, USA). The parameters were set as follows: peptide mass tolerance was $\pm 20 \mathrm{ppm}$, fragment mass tolerance was $0.1 \mathrm{Da}$, and max missed cleavages were set to 2 . TMT-10plex was set as fixed modifications, and oxidation was set as variable modifications. False discovery rate of peptides was set to be $<0.01$. All peptide ratios were normalised by the median protein ratio, and the median protein ratio was defined as 1 after the normalisation.

\section{Protein identification and bioinformatic analysis}

For identification of differentially expressed proteins, the fold change should be $>1.2$ or $<0.83$ with a $P$ value (student's $t$-test $)<0.05$. The gene ontology (GO) annotation of differentially expressed proteins was blasted against SwissProt database (human) using the NCBI BLAST+ client software. Functional annotation was searched against the online Kyoto Encyclopedia of Genes and Genomes (KEGG) database (http://geneontology.org/). GO enrichment and KEGG pathway enrichment were performed based on the Fisher' exact test. Hierarchical clustering was analysed using Cluster 3.0 (http://bonsai.hgc.jp/ mdehoon/software/cluster/software.htm) and the Java Treeview software. The protein-protein interaction (PPI) networks were analysed using IntAct Molecular Interaction Database (http://www.ebi.ac.uk/intact/) and visualised using Cytoscape software.

\section{Immunoblotting}

For immunoblotting analysis, syncytiotrophoblast tissue was homogenised in RIPA buffer containing protease inhibitors and quantified with the BCA Protein Assay Kit. The protein bands were detected and imaged using a capillary-based western blot automated system ProteinSimple WES with anti-vascular endothelial growth factor receptor 1 (FLT1, 1:1000, Proteintech, 13,687-1-AP), anti-polyadenylate-binding protein 4 (PABPC4, 1:1000, Proteintech, 14,960-1-AP), and anti-glyceraldehyde-3-phosphate dehydrogenase (GAPDH, 1:1000, Proteintech, 10,494-1-AP).

\section{Results \\ Characteristics of the patients}

Table 1 shows the clinical characteristics of patients with GDM and patients with GDM with subsequently developed $\mathrm{PE}$. The maternal age, parity, pregnancy BMI at 12 week, gestation age at delivery, gestation age at 75-g OGTT, and glucose concentrations of 0 and $2 \mathrm{~h}$ OGTT in patients with GDM did not differ significantly from those in patients with GDM with subsequently developed PE. Systolic and diastolic blood pressures, as well as insulin concentration, were significantly higher in patients with GDM with subsequently developed PE than that in patients with GDM $(P<0.05)$. The 
Table 1 Clinical characteristics of patients with GDM and patients with GDM with subsequently developed PE (GDM/PE)

\begin{tabular}{|c|c|c|c|}
\hline & GDM & GDM/PE & $P$ value \\
\hline Sample size $(n)$ & 9 & 9 & \\
\hline Maternal age (years) & $32.67 \pm 5.12$ & $30.22 \pm 3.90$ & 0.107 \\
\hline Parity & $0.44 \pm 0.53$ & $0.33 \pm 0.47$ & 0.681 \\
\hline Pregnancy BMI at 12 week $\left(\mathrm{kg} / \mathrm{m}^{2}\right)$ & $25.76 \pm 2.56$ & $25.93 \pm 2.14$ & 0.824 \\
\hline Gestation age at delivery (wk) & $38.49 \pm 0.98$ & $33.97 \pm 1.05$ & $<0.001^{*}$ \\
\hline Gestation age at 75-g OGTT (wk) & $24.70 \pm 040$ & $24.81 \pm 0.49$ & 1.100 \\
\hline OGTT 0 h glucose $(\mathrm{mmol} / \mathrm{L})$ & $5.46 \pm 0.64$ & $5.31 \pm 0.27$ & 0.533 \\
\hline OGTT $2 \mathrm{~h}$ glucose $(\mathrm{mmol} / \mathrm{L})$ & $7.36 \pm 1.12$ & $8.43 \pm 1.39$ & $0.027^{*}$ \\
\hline Insulin (mU/L) & $11.73 \pm 1.79$ & $15.17 \pm 3.09$ & $0.046^{*}$ \\
\hline Maximum SBP (mmHg) & $131.33 \pm 5.70$ & $186.44 \pm 11.59$ & $<0.001^{*}$ \\
\hline Maximum DBP $(\mathrm{mmHg})$ & $85.22 \pm 4.58$ & $121.89 \pm 9.46$ & $<0.001^{*}$ \\
\hline Proteinuria (g/24 h) & $0.01 \pm 0.01$ & $5.56 \pm 1.65$ & $<0.001^{*}$ \\
\hline
\end{tabular}

protein contents in a 24-h urine collection in all of the patients with GDM with subsequently developed PE were 5.56 $\pm 1.65 \mathrm{~g}$, while those in all of the patients with GDM were $0.01 \pm 0.01 \mathrm{~g}$. It is worth noting that, without medication, all of the diagnoses of PE in patients with GDM in our study were severe and before 34 weeks (data not shown), suggesting that GDM promotes the development of severe early-onset PE.

\section{Protein identification}

A total of 28,234 unique peptides and 4140 proteins were identified in all samples. According to protein identification criteria, 23 differentially expressed proteins were found in comparison between the patients with PE with GDM and patients with GDM (Table 2). Among them, 11 proteins were upregulated, and 12 proteins were downregulated. The K-means clustering of these differentially expressed proteins is shown in a heat map (Fig. 1).

\section{Immunoblotting verification}

To verify the expression levels of differentially expressed proteins discovered by TMT analysis, immunoblotting was performed to investigate the expression patterns of FLT1 and PABPC4, two proteins in the same samples. GAPDH was chosen as an internal control. The results showed that FLT1 was expressed at higher levels, while PABPC4 was expressed at lower levels in PE with GDM groups than in GDM groups (Fig. 2), suggesting that the immunoblotting results were in line with TMT proteomics results.

\section{Bioinformatic analysis}

Figure 3 shows the top 20 rankings of biological process, molecular function, and cellular component based on GO annotation. The main biological process of these differentially expressed proteins was regulation of extrinsic apoptotic signalling pathway, regulation of transcription from RNA polymerase, cellular modified amino acid metabolic process, selenium compound metabolic process, establishment or maintenance of polarity of follicular epithelium, and animal organ senescence. The main molecular function of these proteins was associated with methylselenol reductase activity, 15-hydroxyprostaglandin dehydrogenase activity, diamine oxidase activity, histamine oxidase activity, and icosanoid receptor activity. The main cellular component was ribonuclease $\mathrm{H} 2$ complex, $\mathrm{CHOP}$-activating transcription factor 3 complex, actomyosin, actin portion, and cornified envelope. By KEGG pathway analysis, 4 differentially expressed proteins were enriched into histidine metabolism and transcriptional misregulation in cancer pathways (Fig. 4). By PPI analysis, 7 differentially expressed proteins (WDR1, FLT1, MUC1, ANXA4, ERO1A, ATF3, and PABPC4) interacted with each other and enriched into a larger protein interaction network. The other 10 differentially expressed proteins (KIF1BP, NDUFV3, and GSTA3; ASPSCR1 and MRGBP; AHCYL2 and TCHH; TXNRD1; RNASEH2C; and PAPP-A2) enriched into different protein interaction network, respectively (Fig. 5). These results suggested that occurrence of PE in women with GDM is the result of multiple pathway dysfunction.

\section{Discussion}

Although studies have revealed that GDM is one of the risk factors for developing $\mathrm{PE}$, the pathogenesis remains unclear. To clarify the molecular mechanisms and search the potential biomarkers for PE screening from women with GDM, we identified and quantified differentially expressed proteins from women with GDM with subsequently developed PE compared with GDM women. The results showed that a total of 23 proteins expressed differentially between the two groups. These proteins involved in different biological functions and signalling 
Table 2 The differentially expressed proteins identified in syncytiotrophoblast from patients with GDM with subsequently developed PE and patients with GDM

\begin{tabular}{|c|c|c|c|c|}
\hline Protein name & Accession No & Gene name & Fold change & $P$ value \\
\hline WD repeat-containing protein 1 & 075083 & WDR1 & 1.600 & 0.026 \\
\hline Vascular endothelial growth factor receptor 1 & P17948 & FLT1 & 1.377 & 0.031 \\
\hline 15-hydroxyprostaglandin dehydrogenase & P15428 & HPGD & 1.366 & 0.015 \\
\hline Ribonuclease $\mathrm{H} 2$, subunit $\mathrm{C}$ & E9PKPO & RNASEH2C & 1.339 & 0.001 \\
\hline Amine oxidase & D3DX03 & ABP1 & 1.311 & 0.003 \\
\hline cDNA FLJ51917 & B4DNZ4 & N/A & 1.261 & 0.040 \\
\hline Mucin 1 & B6ECB2 & MUC1 & 1.256 & 0.049 \\
\hline Annexin A4 & P09525 & ANXA4 & 1.251 & 0.049 \\
\hline cDNA FLJ38330 & Q8N959 & N/A & 1.235 & 0.045 \\
\hline Pappalysin-2 & Q9BXP8 & PAPPA2 & 1.221 & 0.015 \\
\hline ERO1-like protein 1 alpha & Q96HE7 & ERO1A & 1.205 & 0.011 \\
\hline KIF 1-binding protein & Q96EK5 & KIF1BP & 0.826 & 0.047 \\
\hline Activating transcription factor 3 & Q7Z567 & ATF3 & 0.823 & 0.041 \\
\hline Thioredoxin reductase 1 & E9PIR7 & TXNRD1 & 0.822 & 0.027 \\
\hline cDNA FLJ16285 & B3KV96 & N/A & 0.815 & 0.035 \\
\hline NADH dehydrogenase flavoprotein 3 & P56181 & NDUFV3 & 0.815 & 0.010 \\
\hline Glutathione S-transferase A3 & Q5JW85 & GSTA3 & 0.802 & 0.045 \\
\hline Tether containing UBX domain for GLUT4 & J3QL04 & ASPSCR1 & 0.795 & 0.037 \\
\hline Trichohyalin & Q07283 & $\mathrm{TCHH}$ & 0.789 & 0.044 \\
\hline Solute carrier family 13 & Q59HF0 & N/A & 0.781 & 0.009 \\
\hline MRG/MORF4L-binding protein & Q9NV56 & MRGBP & 0.776 & 0.042 \\
\hline Adenosylhomocysteinase 2 & Q96HN2 & AHCYL2 & 0.746 & 0.028 \\
\hline Polyadenylate-binding protein 4 & B1ANRO & PABPC4 & 0.744 & 0.025 \\
\hline
\end{tabular}

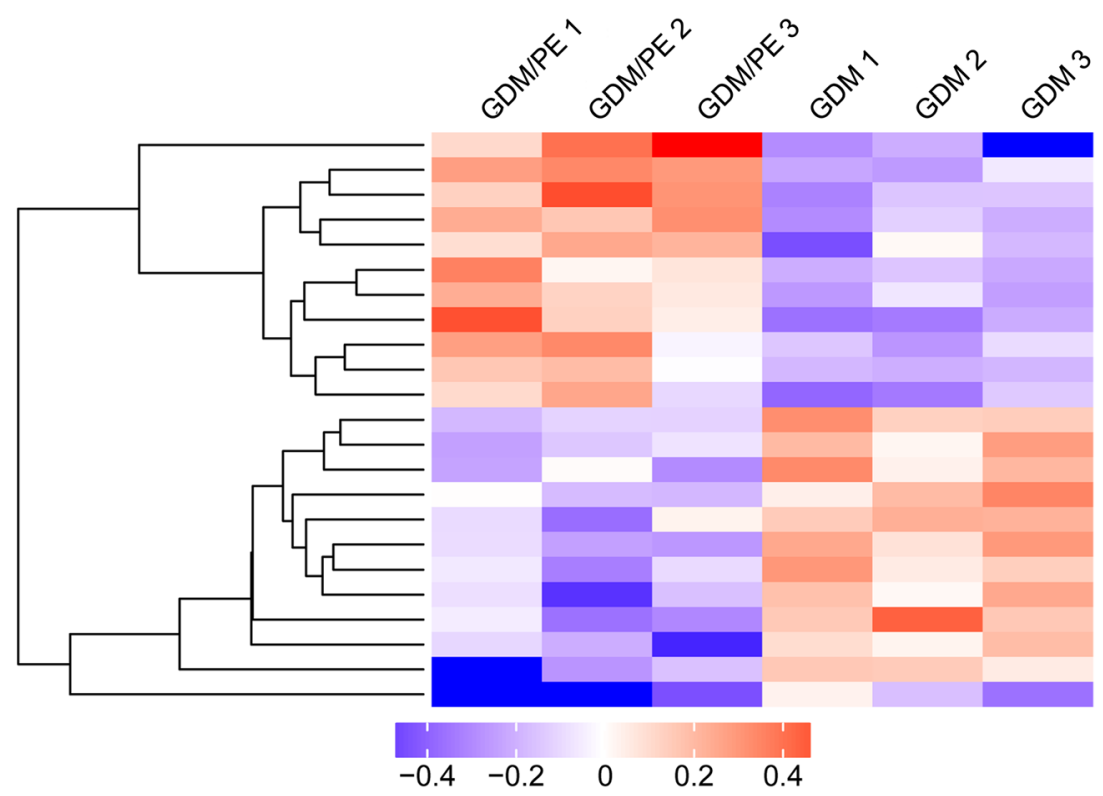

075083

E9PKPO

P15428

D3DX03

B4DNZ4

Q8N959

Q9BXP8

17948

P09525

Q96HE7

B6ECB2

P56181

E9PIR7

Q5JW85

Q96EK5

B3KV96

Q59HFO

Q7Z567

Q07283

B1ANRO

J3QL04

Q96HN2

$\begin{array}{lllll}-0.4 & -0.2 & 0 & 0.2 & 0.4\end{array}$

9NV6

Fig. $1 \mathrm{~K}$-means clustering of differentially expressed proteins identified in human syncytiotrophoblast 


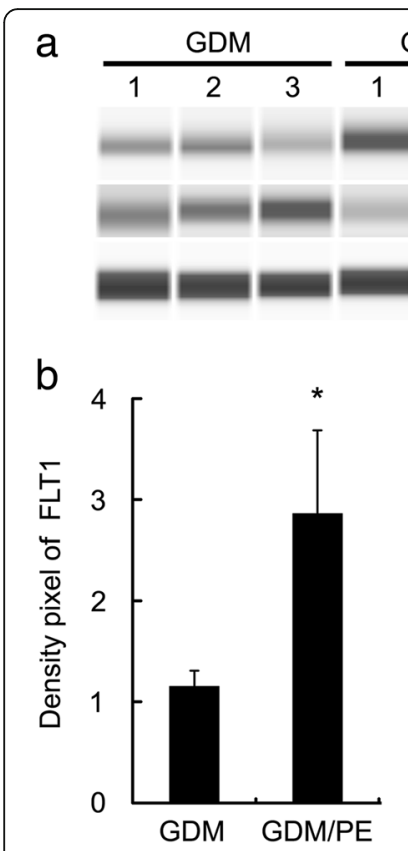

GDM/PE

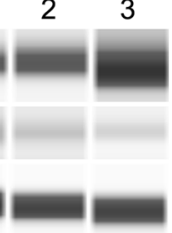

\section{IB:} anti-FLT1 anti-PABPC4 anti-GAPDH

Fig. 2 Immunoblotting analysis with anti-FLT1, anti-PABPC4 and anti-GAPDH antibodies was performed on patients with GDM and patients with GDM with subsequently developed PE (a). Comparison of protein expression levels of FLT1 (b) and PABPC4 (c) in patients with GDM with subsequently developed PE and patients with GDM groups. The $\mathrm{Y}$-axis represents the relative quantification of target proteins normalised to GAPDH. The minimum mean of band density pixels was taken as 1

pathway implied that multiple mechanisms contribute to the development of PE from women with GDM.

Of the 23 differentially expressed proteins, 7 have been reported to be implicated in the onset of PE. In our study, 5 of these proteins have upregulated expression, such as FLT1, MUC1, ANXA4, PAPP-A2, and HPGD. Two proteins were downregulated, such as ATF3 and TXNRD1.

As a transcriptional repressor, ATF3 is induced rapidly when cells are exposed to a wide range of stress stimuli. The increased ATF3 prevents cells from tumour necrosis factor alpha (TNF- $\alpha$ )-induced apoptosis by inhibiting tumour suppressor gene p53 transcription and cleavage of procaspase 3. Thus, ATF3 may maintain the survival of endothelial cells during vascular inflammation and atherosclerosis [21]. In preeclamptic placentas, both mRNA and protein expression levels of ATF3 were decreased. This reduction was likely to occur after prolonged hypoxia. The decrease of ATF3 expression increased cytokine interleukin 6 , TNF- $\alpha$, and nuclear factor kappaB (NF- $\mathrm{kB}$ ) expression as well as Flt-1 secretion [22]. FLT1 is produced in the placenta and can be detected in the placenta, amniotic fluid, and serum [23-25]. The function of FLT1 is to antagonise vascular endothelial growth factor (VEGF) effects on the formation of placental vasculature and maternal endothelial cell function [24]. The increase of FLT1 protein level is an important risk factor leading to impaired placental angiogenesis [26]. In fact, the expression level of FLT1 in serum of the large number of women with PE were significantly elevated [27-31], while after $48 \mathrm{~h}$ of delivery, the level of FLT1 in serum decreased dramatically [32, 33]. Patients with GDM tend to develop dysfunction of vascular endothelial cells and atherosclerosis, leading to PE [15]. Therefore, ATF3-FLT1 axis may be the primary pathogenesis of women with GDM to secondarily developed PE.

MUC1, with a large mucin-like extracellular domain, locates on the surface of cells. Overexpression of MUC1 reduces cell-cell interactions and inhibits integrin-mediated cell adhesion to the extracellular matrix [34]. Immunohistochemical and immunoblotting analysis showed that the expression levels of MUC1 in the syncytiotrophoblast and extravillous trophoblast cells (EVT) of severe preeclamptic placentas were increased. MUC1 overexpression suppressed cell-matrix adhesion and EVT invasion [35], probably leading to insufficient infiltration of syncytiotrophoblast cells into the endometrium.

ANXA4 is a $\mathrm{Ca}^{2+}$-dependent phospholipid binding protein, specifically expressing on the basal surface of syncytiotrophoblast. The increased activity of phospholipase A2 would lead to more arachidonic acid decomposing into thromboxane A2, which results in coagulation subsequently. Therefore, after delivery, ANXA4 enters the maternal bloodstream and prevent the activation of blood coagulation [36]. In gallbladder cancer tissues, the ANXA4 gene was highly expressed. Moreover, the elevated ANXA4 expression correlated well with invasion depth in patients with gallbladder cancer. One reason is that upregulated expression of ANXA4 promotes tumour cell growth, migration, and invasion by activating NF- $\kappa B$ pathway [37]. NF- $\kappa B$ plays important roles in the cell proliferation, inflammation, angiogenesis, apoptosis, invasion, and cellular adhesion, which also are important features in pathogenesis of PE. Using 2D electrophoresis combined with MALDI-TOF-MS, ANXA4 was identified as one of the 11 upregulated expressed proteins from preeclamptic placenta compared to that of normal pregnancy. This result is the first finding that there is a relationship between upregulated ANXA4 and the occurrence of PE [38]. In our study, ANXA4 also has upregulated expression in patients with GDM with subsequently developed PE compared to patients with GDM. The involved common mechanism should be further studied in detail.

Insulin-like growth factors (IGFs) and their binding proteins (IGFBPs) play important roles during establishment of pregnancy and placental development by mediating cell communication between trophoblasts and deciduae, as well as promoting trophoblast invasion [39]. PAPP-A2, also named pregnancy-associated plasma protein-A2, is capable of cleaving IGFBP5 specifically to regulate its biological function [40]. Both mRNA and protein expression levels of PAPP-A2 were upregulated in severe early-onset preeclamptic placentas and 

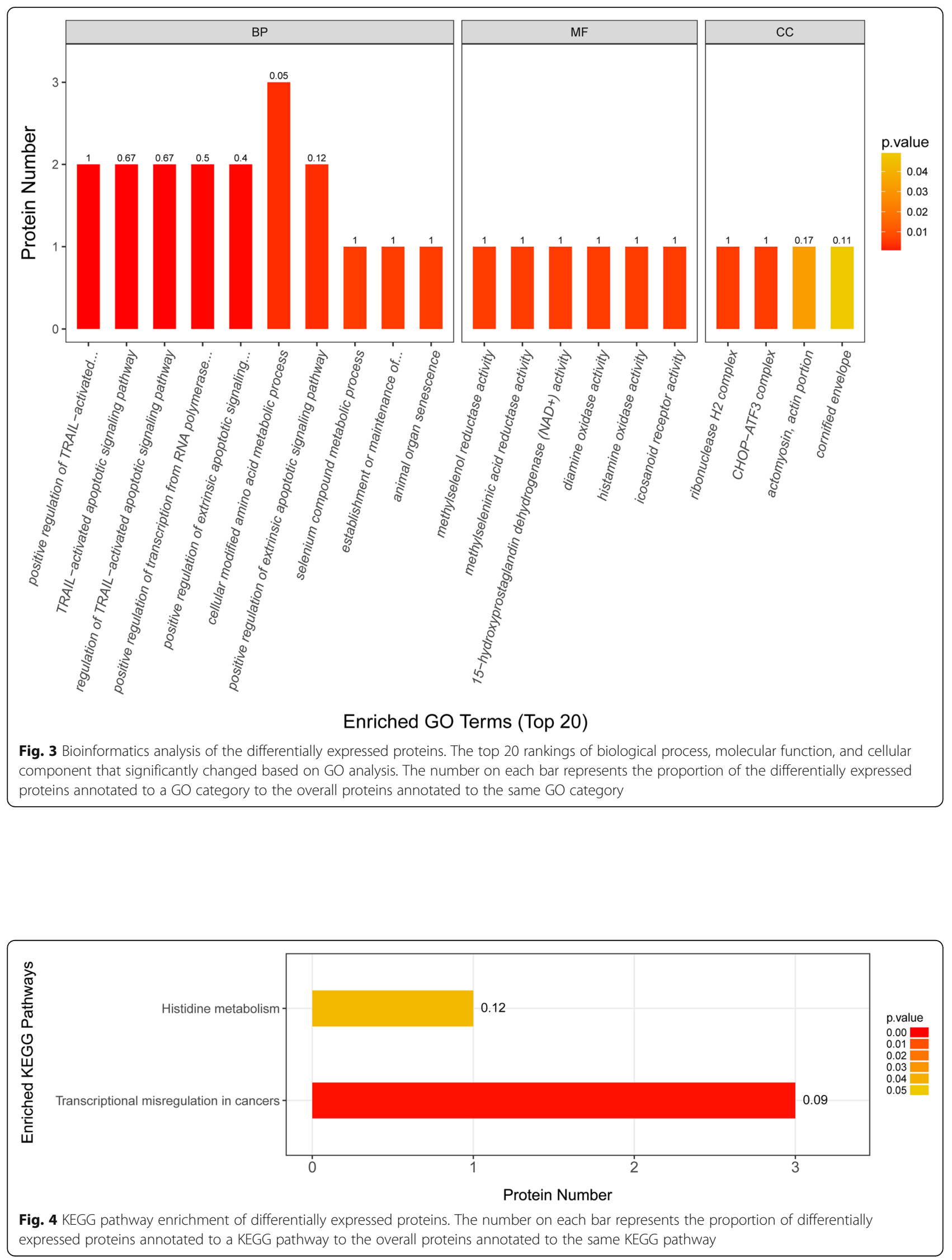


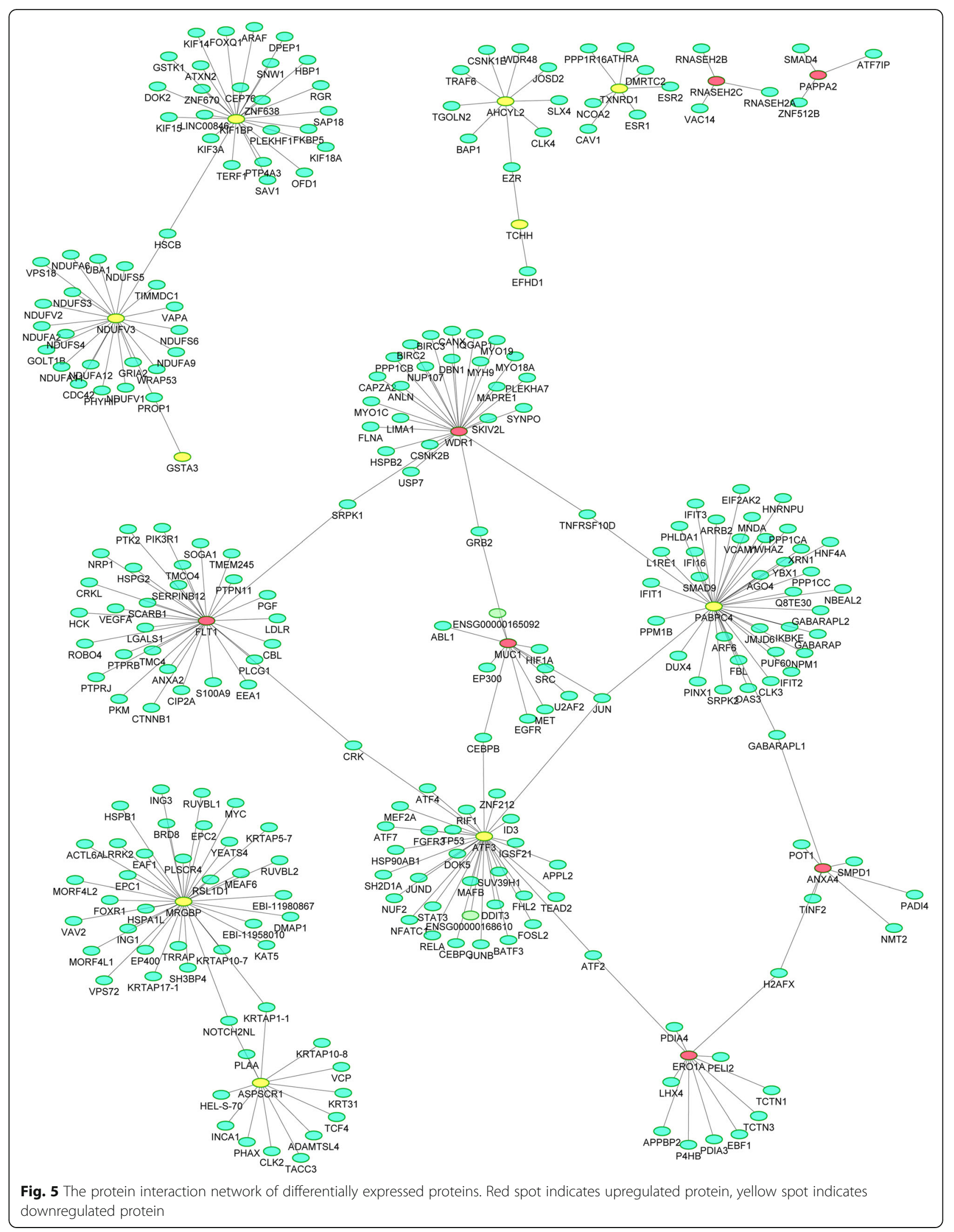


localised to the syncytiotrophoblast [41]. The upregulated PAPP-A2 may degrade IGFBP5 and then inhibit trophoblast invasion. However, a study has also shown that hypoxia and TNF- $\alpha$, but not oxidative stress, contributed to the upregulation of PAPPA2, suggesting that PAPPA2 is upregulated as a consequence, rather than a cause of PE [42]. Due to the increased concentration of PAPP-A2 in serum in agreement with that in placenta, PAPP-A2 has a potential as a biomarker for the onset of PE [43].

Oxidative stress damages placental tissue resulting in intrauterine growth retardation and foetal distress, involving in the pathogenesis of PE. Thioredoxin reductase was located in the cytoplasm and mitochondria of cytotrophoblasts and deciduae in the placenta. It may protect the placenta against oxidative stress by reducing reactive oxygen species [44]. The decreased protein expression level of TXNRD1 may be attributed to patients with GDM with PE.

As a cancer suppressor, the expression level of HPGD is decreased in several tumour cells. The decreased HPGD blocks the production of the prostaglandin E2 (PGE2) metabolite, which can promote cancer progression by modulating tumour cells of proliferation, migration, invasion, angiogenesis, and apoptosis [45]. In a previous study, the mRNA level of HPGD in the placenta of patients with PE was decreased [46], while in our study, the protein level of HPGD was increased, implying that gene expression of HPGD might be regulated by negative feedback. Therefore, the increased HPGD protein in our study may also interfere syncytiotrophoblast cells of proliferation, migration, invasion, angiogenesis, and apoptosis. This finding is worthy of further investigation.

In addition, ERO1A, upregulated in our study, was strongly induced by hypoxia, involving in oxidative endoplasmic reticulum protein folding and inhibition of VEGF-driven angiogenesis [47]. Although the function of inhibiting VEGF-driven angiogenesis is similar to that of FLT1, the relationship between ERO1A and onset of PE remains unknown. More studies are required to investigate whether ERO1A is involved in the pathogenesis of PE and can be used as a potential biomarker.

Subsequently, we selected two proteins, FLT1, involved in the key processes as mentioned above, and PABPC4, verified by immunoblotting analysis. The expression pattern of these proteins was consistent with the proteomics results. Finally, bioinformatic analysis revealed that the differentially expressed proteins mainly enriched to apoptosis function and transcriptional misregulation in cancer pathways. These results implied that the regulation mechanism of syncytiotrophoblast on the invasion and migration of endometrium may be similar to that of tumour cells. Patients with GDM are more likely to have misregulation of transcription, angiogenic disorder, and oxidative stress, which lead to insufficient infiltration of syncytiotrophoblast cells and dysfunction of apoptosis, subsequently leading to the onset of severe early-onset PE. Further research and verification are needed to explore the possible.

Limitation of our study was that the sample size was small, for it is a little difficult to recruit more patients with strict inclusion criteria. A large number of experimental samples from different hospitals will be required to verify and obtain further arguments in future study. Moreover, proteomics studies of placental tissue are not the only way to confirm our findings, protein-related studies of fetal appendages such as blood, urine, and amniotic fluid are also feasible. Therefore, we hope that there will be more research on preeclampsia in the future.

\section{Conclusion}

In this study, we performed TMT proteomic analysis on syncytiotrophoblast to compare the differentially expressed proteins. Twenty-three protein expressions were identified as significant differences between patients with GDM and patients with GDM with subsequently developed PE. Some of these differentially expressed proteins have been confirmed to be involved in the development of PE. Bioinformatic results indicated that the onset of PE form GDM patients also is a multifactorial disorder, involving in apoptosis, transcriptional misregulation, oxidative stress, cell infiltration and migration, angiogenesis, etc. Our results show that the inadequacy of endometrium infiltration, dysfunction of apoptosis, angiogenic disorder, and oxidative stress in syncytiotrophoblast cells more likely occur in GDM patients. These processes may be the potential mechanisms leading to GDM patients to secondarily developed severe early-onset PE. Thus, these proteins can also be considered as candidate biomarkers for predicting the onset of PE from women with GDM or as an intervention target for preventing GDM from developing into PE.

\section{Abbreviations}

BMI: Body mass index; DBP: Diastolic blood pressure; EVT: Extravillous trophoblast cells; FABP4: Fatty acid-binding protein 4; FASP: Filter-aided sample preparation; FLT1: Vascular endothelial growth factor receptor 1; GAPDH: Glyceraldehyde-3-phosphate dehydrogenase; GDM: Gestational diabetes mellitus; GO: Gene ontology; HCD: Higher-energy collisional dissociation; HPGD: 15-hydroxyprostaglandin dehydrogenase; IGFBPs: Insulinlike growth factor binding proteins; IGFs: Insulin-like growth factors; KEGG: Kyoto encyclopedia of genes and genomes; LC-MS/MS: Liquid chromatography-mass spectrometry/ mass spectrometry; NF-KB: Nuclear factor kappaB; OGTT: Oral glucose tolerance test; PABPC4: Polyadenylatebinding protein 4; PE: Preeclampsia; PGE2: Prostaglandin E2; PPI: Proteinprotein interaction; SBP: Systolic blood pressure; TMT: Tandem mass tag; TNF-a: Tumour necrosis factor alpha; VEGF: Vascular endothelial growth factor

\section{Acknowledgements}

We thank all mothers for consenting to participate in this study and provide their information, and Editage for providing professional writing services.

\section{Funding}

This research was supported by Gansu Provincial Commission of Health and Family Planning (No. GSWSKY2016-48), Gansu Provincial Hospital (No. 17GSSY2-3 and 16GSSY4-4), and Lanzhou science and technology program (No. 2017-4-68). 


\section{Availability of data and materials}

No datasets were generated or analysed during the study.

\section{Authors' contributions}

XS1 conceived the study design, interviewed mother for each case, and wrote the manuscript. TQ performed the experiments and analysed the data. $\mathrm{XH}$ and $\mathrm{XY}$ collected samples for each case and reviewed relevant background research. NG and YM reviewed medical records and assisted in analysis of the data. XX assisted in interpretation of medical record data. XS2 advised in designing the study. XZ and WW advised in designing the study and revised the manuscript. All authors read and approved the final manuscript.

\section{Ethics approval and consent to participate}

The study was approved by the Ethical Committee of the Gansu Provincial Hospital. All study participants agreed to the sample collection and provided written informed consent.

\section{Consent for publication}

All mothers provided written informed consent to publish their individual information.

\section{Competing interests}

The authors declare that they have no competing interests.

\section{Publisher's Note}

Springer Nature remains neutral with regard to jurisdictional claims in published maps and institutional affiliations.

\section{Author details}

${ }^{1}$ The First Clinical Medical College, Lanzhou University, Lanzhou, China. 2Department of Obstetrics, Gansu Provincial Hospital, Lanzhou, China. ${ }^{3}$ Department of Biotherapy Center, Gansu Provincial Hospital, Lanzhou, China. ${ }^{4}$ Department of Endocrinology, Affiliated Hospital of Weifang Medical University, Weifang, China. ${ }^{5}$ The Reproductive Medicine Special Hospital of the First Hospital of Lanzhou University, Lanzhou, China. ${ }^{6}$ Key Laboratory for Reproductive Medicine and Embryo of Gansu, Lanzhou, China. ${ }^{7}$ Houston Fertility Laboratory, Houston, TX, USA.

Received: 3 August 2018 Accepted: 19 October 2018

Published online: 07 November 2018

\section{References}

1. Steegers EA, von Dadelszen P, Duvekot JJ, Pijnenborg R. Pre-eclampsia. Lancet. 2010;376(9741):631-44.

2. Saleem S, McClure EM, Goudar SS, Patel A, Esamai F, Garces A, Chomba E, Althabe F, Moore J, Kodkany B, et al. A prospective study of maternal, fetal and neonatal deaths in low- and middle-income countries. Bull World Health Organ. 2014;92(8):605-12.

3. Auer J, Camoin L, Guillonneau F, Rigourd V, Chelbi ST, Leduc M, Laparre J, Mignot TM, Vaiman D. Serum profile in preeclampsia and intra-uterine growth restriction revealed by iTRAQ technology. J Proteome. 2010;73(5):1004-17.

4. Montoro MN, Kjos SL, Chandler M, Peters RK, Xiang AH, Buchanan TA. Insulin resistance and preeclampsia in gestational diabetes mellitus. Diabetes Care. 2005;28(8):1995-2000.

5. von Dadelszen P, Magee LA, Roberts JM. Subclassification of preeclampsia. Hypertens Pregnancy. 2003;22(2):143-8.

6. Nadeau-Vallee M, Obari D, Palacios J, Brien ME, Duval C, Chemtob S, Girard S. Sterile inflammation and pregnancy complications: a review. Reproduction. 2016;152(6):R277-92.

7. Nelson DB, Ziadie MS, McIntire DD, Rogers BB, Leveno KJ: Placental pathology suggesting that preeclampsia is more than one disease. Am J Obstet Gynecol 2014, 210(1):66 e61-67.

8. Villa PM, Marttinen P, Gillberg J, Lokki Al, Majander K, Orden MR, Taipale P, Pesonen A, Raikkonen $\mathrm{K}$, Hamalainen $\mathrm{E}$, et al. Cluster analysis to estimate the risk of preeclampsia in the high-risk prediction and prevention of preeclampsia and intrauterine growth restriction (PREDO) study. PLoS One. 2017;12(3):e0174399.

9. Singh A, Subramani E, Datta Ray C, Rapole S, Chaudhury K. Proteomic-driven biomarker discovery in gestational diabetes mellitus: a review. J Proteome. 2015;127(Pt A):44-9.
10. Schneider S, Freerksen N, Rohrig S, Hoeft B, Maul H. Gestational diabetes and preeclampsia--similar risk factor profiles? Early Hum Dev. 2012;88(3):179-84.

11. Mrema D, Lie RT, Ostbye T, Mahande MJ, Daltveit AK. The association between pre pregnancy body mass index and risk of preeclampsia: a registry based study from Tanzania. BMC Pregnancy Childbirth. 2018;18(1):56.

12. Nerenberg KA, Johnson JA, Kaul P. Risk of preeclampsia in pregnant women with gestational diabetes in Alberta. Pregnancy Hypertens. 2012;2(3):323-4.

13. Ostlund I, Haglund B, Hanson U. Gestational diabetes and preeclampsia. Eur J Obstet Gynecol Reprod Biol. 2004;113(1):12-6.

14. Phaloprakarn C, Tangjitgamol S. Risk assessment for preeclampsia in women with gestational diabetes mellitus. J Perinat Med. 2009;37(6):617-21.

15. Llurba E, Casals E, Dominguez C, Delgado J, Mercade I, Crispi F, MartinGallan P, Cabero L, Gratacos E. Atherogenic lipoprotein subfraction profile in preeclamptic women with and without high triglycerides: different pathophysiologic subsets in preeclampsia. Metabolism. 2005;54(11):1504-9.

16. Qi WH, Zheng MY, Li C, Xu L, XU JE. Screening of differential proteins of placenta tissues in patients with pre-eclampsia by iTRAQ proteomics techniques. Minerva Med. 2017;108(5):389-95.

17. Kolla V, Jeno P, Moes S, Lapaire O, Hoesli I, Hahn S. Quantitative proteomic (iTRAQ) analysis of 1st trimester maternal plasma samples in pregnancies at risk for preeclampsia. J Biomed Biotechnol. 2012;2012:305964.

18. Li H, Han L, Yang Z, Huang W, Zhang X, Gu Y, Li Y, Liu X, Zhou L, Hu J, et al. Differential proteomic analysis of Syncytiotrophoblast extracellular vesicles from early-onset severe preeclampsia, using 8-Plex iTRAQ labeling coupled with 2D Nano LC-MS/MS. Cell Physiol Biochem. 2015;36(3):1116-30.

19. Pan HT, Guo MX, Xiong YM, Ren J, Zhang JY, Gao Q, Ke ZH, Xu GF, Tan YJ, Sheng JZ, et al. Differential proteomic analysis of umbilical artery tissue from preeclampsia patients, using iTRAQ isobaric tags and 2D nano LC-MS/MS. J Proteome. 2015;112:262-73.

20. Li B, Yang H, Zhang W, Shi Y, Qin S, Wei Y, He Y, Yang W, Jiang S, Jin H. Fatty acid-binding protein 4 predicts gestational hypertension and preeclampsia in women with gestational diabetes mellitus. PLoS One. 2018;13(2):e0192347.

21. Kawauchi J, Zhang C, Nobori K, Hashimoto Y, Adachi MT, Noda A, Sunamori M, Kitajima S. Transcriptional repressor activating transcription factor 3 protects human umbilical vein endothelial cells from tumor necrosis factoralpha-induced apoptosis through down-regulation of p53 transcription. J Biol Chem. 2002;277(41):39025-34.

22. Kaitu'U-Lino TJ, Brownfoot FC, Hastie R, Chand A, Cannon P, Deo M, Tuohey L, Whitehead C, Hannan NJ, Tong S. Activating transcription factor 3 is reduced in Preeclamptic placentas and negatively regulates sFlt-1 (soluble fms-like tyrosine kinase 1), soluble Endoglin, and Proinflammatory cytokines in placenta. Hypertension. 2017;70(5):1014-24.

23. He B, Yang X, Li Y, Huang D, Xu X, Yang W, Dai Y, Zhang H, Chen Z, Cheng W. TLR9 (toll-like receptor 9) agonist suppresses angiogenesis by differentially regulating VEGFA (vascular endothelial growth factor a) and sFLT1 (soluble vascular endothelial growth factor receptor 1 ) in preeclampsia. Hypertension. 2018;71(4):671-80.

24. Koga K, Osuga Y, Yoshino O, Hirota Y, Ruimeng X, Hirata T, Takeda S, Yano T, Tsutsumi O, Taketani Y. Elevated serum soluble vascular endothelial growth factor receptor 1 (sVEGFR-1) levels in women with preeclampsia. J Clin Endocrinol Metab. 2003;88(5):2348-51.

25. Vuorela P, Helske S, Hornig C, Alitalo K, Weich H, Halmesmaki E. Amniotic fluid--soluble vascular endothelial growth factor receptor-1 in preeclampsia. Obstet Gynecol. 2000;95(3):353-7.

26. Ahmad S, Ahmed A. Elevated placental soluble vascular endothelial growth factor receptor-1 inhibits angiogenesis in preeclampsia. Circ Res. 2004;95(9):884-91.

27. Levine RJQC, Maynard SE, Yu KF, Epstein FH, Karumanchi SA. Serum sFlt1 concentration during preeclampsia and mid trimester blood pressure in healthy nulliparous women. Am J Obstet Gynecol. 2006;194:1034-41.

28. Palmer KRK-LT, Hastie R, Hannan NJ, Ye L, Binder N, Cannon P, Tuohey L, Johns TG, Shub A, et al. Placental-specific sFLT-1 e15a protein is increased in preeclampsia, antagonizes vascular endothelial growth factor signaling, and has antiangiogenic activity. Hypertension. 2015;66:1251-9.

29. Levine RJMS, Qian C, Lim K-H, England LJ, Yu KF, Schisterman EF, Thadhani $\mathrm{R}$, Sachs BP, Epstein FH, et al. Circulating Angiogenic factors and the risk of preeclampsia. N Engl J Med. 2004;350:672-83.

30. Shibata ERA, Powers RW, Larkin RW, Gilmour C, Bodnar LM, Crombleholme WR, Ness RB, Roberts JM, Hubel CA. Soluble fms-like tyrosine kinase 1 is increased in preeclampsia but not in normotensive pregnancies with smallfor-gestational-age neonates: relationship to circulating placental growth factor. Endocrinol Metab J Clin. 2005;90:4895-903. 
31. Souders CAMS, Yan J, Wang Y, Boatright NK, Sedan J, Balyozian D, Cheslock PS, Molrine DC, Simas TA. Circulating levels of sFlt1 splice variants as predictive markers for the development of preeclampsia. Int J Mol Sci. 2015; 16:12436-53.

32. McKeeman GCAJ, Caldwell CM, Hunter AJ, McClure N. Soluble vascular endothelial growth factor receptor-1 (sFlt-1) is increased throughout gestation in patients who have preeclampsia develop. Am J Obstet Gynecol. 2004;191:1240-6.

33. Chaiworapongsa TRR, Espinoza J, Bujold E, Mee Kim Y, Goncalves LF, Gomez $R$, Edwin S. Evidence supporting a role for blockade of the vascular endothelial growth factor system in the pathophysiology of preeclampsia. Young Investigator Award. Am J Obstet Gynecol. 2004;190:1541-7.

34. Wesseling J, van der Valk SW, Vos HL, Sonnenberg A, Hilkens J. Episialin (MUC1) overexpression inhibits integrin-mediated cell adhesion to extracellular matrix components. J Cell Biol. 1995;129(1):255-65.

35. Shyu MK, Chen CW, Lin NY, Liao WC, Chen CH, Lin CJ, Huang HC, Lee JJ, Huang MJ, Tseng GF, et al. MUC1 expression is elevated in severe preeclamptic placentas and suppresses trophoblast cell invasion via beta1integrin signaling. J Clin Endocrinol Metab. 2011;96(12):3759-67.

36. Masuda J, Takayama E, Satoh A, Ida M, Shinohara T, Kojima-Aikawa K, Ohsuzu F, Nakanishi K, Kuroda K, Murakami M, et al. Levels of annexin IV and $\mathrm{V}$ in the plasma of pregnant and postpartum women. Thromb Haemost. 2004;91(6):1129-36.

37. Yao HS, Sun C, Li XX, Wang Y, Jin KZ, Zhang XP, Hu ZQ. Annexin A4-nuclear factor-kappaB feedback circuit regulates cell malignant behavior and tumor growth in gallbladder cancer. Sci Rep. 2016;6:31056.

38. Yang Jl, Kong TW, Kim HS, Kim HY. The proteomic analysis of human placenta with pre-eclampsia and Normal pregnancy. J Korean Med Sci. 2015;30(6):770-8.

39. Gratton RJ, Asano H, Han VK. The regional expression of insulin-like growth factor II (IGF-II) and insulin-like growth factor binding protein-1 (IGFBP-1) in the placentae of women with pre-eclampsia. Placenta. 2002;23(4):303-10.

40. Overgaard MT, Boldt HB, Laursen LS, Sottrup-Jensen L, Conover CA, Oxvig C. Pregnancy-associated plasma protein-A2 (PAPP-A2), a novel insulin-like growth factor-binding protein-5 proteinase. J Biol Chem. 2001;276(24):21849-53.

41. Macintire K, Tuohey L, Ye L, Palmer K, Gantier M, Tong S, Kaitu'u-Lino TJ. PAPPA2 is increased in severe early onset pre-eclampsia and upregulated with hypoxia. Reprod Fertil Dev. 2014;26(2):351-7.

42. Wagner PK, Otomo A, Christians JK. Regulation of pregnancy-associated plasma protein A2 (PAPPA2) in a human placental trophoblast cell line (BeWo). Reprod Biol Endocrinol. 2011;9:48.

43. Kloverpris S, Gaidamauskas E, Rasmussen LC, Overgaard MT, Kronborg C, Knudsen UB, Christiansen M, Kumar A, Oxvig C. A robust immunoassay for pregnancy-associated plasma protein-A2 based on analysis of circulating antigen: establishment of normal ranges in pregnancy. Mol Hum Reprod. 2013;19(11):756-63.

44. Ejima K, Nanri H, Toki N, Kashimura M, Ikeda M. Localization of thioredoxin reductase and thioredoxin in normal human placenta and their protective effect against oxidative stress. Placenta. 1999;20(1):95-101.

45. Backlund MG, Mann JR, Holla VR, Buchanan FG, Tai HH, Musiek ES, Milne GL, Katkuri S, DuBois RN. 15-Hydroxyprostaglandin dehydrogenase is downregulated in colorectal cancer. J Biol Chem. 2005;280(5):3217-23.

46. Schoof E, Girstl M, Frobenius W, Kirschbaum M, Dorr HG, Rascher W, Dotsch J. Decreased gene expression of 11 beta-hydroxysteroid dehydrogenase type 2 and 15-hydroxyprostaglandin dehydrogenase in human placenta of patients with preeclampsia. J Clin Endocrinol Metab. 2001;86(3):1313-7.

47. May D, Itin A, Gal O, Kalinski H, Feinstein E, Keshet E. Erol-L alpha plays a key role in a HIF-1-mediated pathway to improve disulfide bond formation and VEGF secretion under hypoxia: implication for cancer. Oncogene. 2005;24(6):1011-20.

Ready to submit your research? Choose BMC and benefit from:

- fast, convenient online submission

- thorough peer review by experienced researchers in your field

- rapid publication on acceptance

- support for research data, including large and complex data types

- gold Open Access which fosters wider collaboration and increased citations

- maximum visibility for your research: over $100 \mathrm{M}$ website views per year

At BMC, research is always in progress.

Learn more biomedcentral.com/submissions 